\title{
Students' perceptions of patient safety during the transition from undergraduate to postgraduate training: an activity theory analysis
}

\author{
Jeantine M. de Feijter • Willem S. de Grave • Tim Dornan • \\ Richard P. Koopmans • Albert J. J. A. Scherpbier
}

Received: 11 August 2010/Accepted: 17 November 2010/Published online: 4 December 2010

(C) The Author(s) 2010. This article is published with open access at Springerlink.com

\begin{abstract}
Evidence that medical error can cause harm to patients has raised the attention of the health care community towards patient safety and influenced how and what medical students learn about it. Patient safety is best taught when students are participating in clinical practice where they actually encounter patients at risk. This type of learning is referred to as workplace learning, a complex system in which various factors influence what is being learned and how. A theory that can highlight potential difficulties in this complex learning system about patient safety is activity theory. Thirty-four final year undergraduate medical students participated in four focus groups about their experiences concerning patient safety. Using activity theory as analytical framework, we performed constant comparative thematic analysis of the focus group transcripts to identify important themes. We found eight general themes relating to two activities: learning to be a doctor and delivering safe patient care. Simultaneous occurrence of these two activities can cause contradictions. Our results illustrate the complexity of learning about patient safety at the workplace. Students encounter contradictions when learning about patient safety, especially during a transitional phase of their training. These contradictions create potential learning opportunities which should be used in education about patient safety. Insight into the complexities of patient safety is essential to improve education in this important area of medicine.
\end{abstract}

Keywords Activity theory - Communities of practice $\cdot$ Patient safety $\cdot$ Workplace learning

J. M. de Feijter $(\bowtie) \cdot$ W. S. de Grave · T. Dornan

Department of Educational Development and Research, Faculty of Health, Medicine and Life

Sciences, Maastricht University, P.O. Box 616, 6200 MD Maastricht, The Netherlands

e-mail: j.defeijter@maastrichtuniversity.nl

R. P. Koopmans

Department of Internal Medicine, Maastricht University Medical Centre+, Maastricht, The Netherlands

A. J. J. A. Scherpbier

Institute for Medical Education, Faculty of Health, Medicine and Life Sciences, Maastricht University, Maastricht, The Netherlands 


\section{Introduction}

The release of the report To err is human by the American Institute of Medicine (IOM) (Kohn et al. 1999), heightened interest in patient safety in the health care community, especially because it was shown that medical errors could harm patients (Brennan et al. 1991; Kohn et al. 1999). The IOM also concluded that medical errors resulted not only from errors by individuals, but also from organisational flaws (Kohn et al. 1999), a conclusion that was generally supported by leading researchers in the field of patient safety (Leape 2009; Reason 2008). Reason (2008) pointed out, however, that medical errors are not exclusively due to one type of error, but can result from a combination of system and individual errors. Indeed, there has been a gradual shift of medical error as an "individual error" towards medical error as both an individual and system error. This conceptual shift has influenced ideas about how and what medical trainees learn and should learn about patient safety. It is increasingly recognised that patient safety education should start at the undergraduate level, particularly in light of evidence that students' knowledge of patient safety is deficient at a wide range of training levels (Kerfoot et al. 2007). Subsequently, the World Health Organization also emphasised the importance of patient safety education in the undergraduate curriculum in its recommendations about a patient safety curriculum (Walton et al. 2008).

Learning about patient safety mostly occurs when trainees are confronted with actual patient safety problems at the clinical workplace (Hall et al. 2010; Walton 2007). Most medical curricula are arranged in such a way that students become progressively more independent, the importance of which is underlined by Kennedy et al. (2005). With the increase in independence students will also be increasingly confronted with problems concerning the safety of patients. Particularly during the transition from clerkships to residency, students encounter situations in which problems (Luthy et al. 2004), including ones where patients are at risk, may be present. Such problems and the concepts that underlie the assurance of patient safety are usually not learned in a formal way, but more informally, while students are participating in daily practice (Fischer et al. 2006; KarnieliMiller et al. 2010; Pingleton et al. 2009).

When students are participating in clinical practice, they enter a highly complex system of workplace learning, in which various interactions affect task performance as well as how and what students learn (Mennin 2010). In designing courses on the principles of patient safety, educators should be mindful of this complexity (Mennin 2010). In order to do justice to this complexity we used activity theory (AT) as a framework to capture the intricacies of learning about patient safety.

cOriginating in cultural-historical psychology, as initiated by Vygotsky, Leont'ev and Luria, and expanded by Engeström (Engeström 2001; Engeström et al. 1999; Vygotsky 1978), AT offers a framework for describing interactions of people, tools (i.e. artefacts) and rules within complex systems. The unit of analysis in AT is the activity system (Engeström 2001) which can be visualised as a triangle at different points of which system components and their interactions (Fig. 1) are situated. Central to an activity is the subject attempting to bring about change (the object) in order to reach a goal (outcome). When we translate this system to medical education, we find students (subject) working to change their skills (object) so as to be able to perform a certain procedure, for instance an abdominal examination (outcome). This process is mediated by the use of tools (artefacts), like a stethoscope. Rules dictate how the tool is to be used, for instance how the stethoscope is to be positioned. The community consists of the student's supervisor and his or her colleagues. Finally, division of labour describes the roles of the members of the community involved in the activity system: the student performing the abdominal examination and the supervisor evaluating the student's performance. All 
Fig. 1 Second generation activity system (Engeström et al. 1999). The subject tries to change something (object) in order to achieve a goal (outcome). This is mediated by tools (artefacts), the rules that apply in that activity, the community that is involved in the activity and the division of labour between members of the community

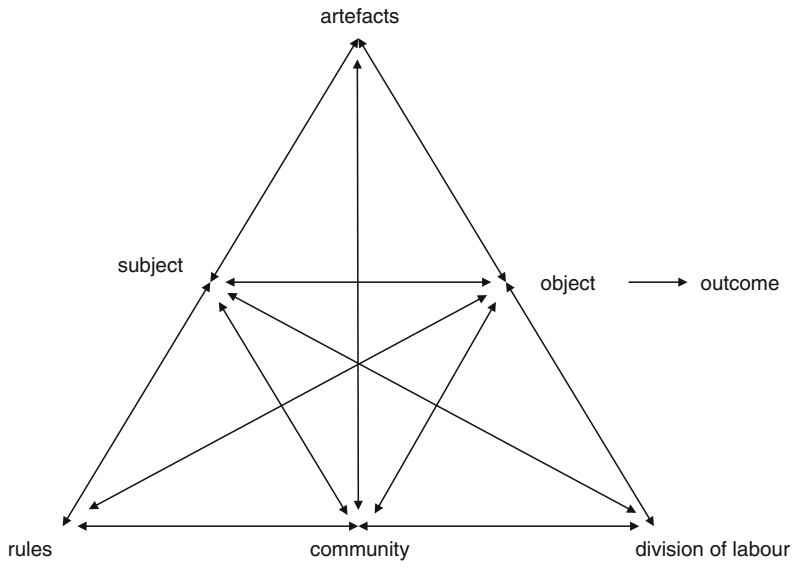

components of an activity system are influenced by cultural and historical factors. Another important characteristic of AT is the central role of contradictions as triggers for change (Engeström 2001). These contradictions can be seen as tensions between and within an activity system and can create conflict, but at the same time present opportunities for change and learning. In the above example a contradiction could arise when the student's findings on abdominal examination differ from those of his supervisor. Learning can be seen to occur when the contradiction prompts the student to change his examination technique.

In this paper we want to focus on the system of learning about patient safety by final year students as the unit of analysis. As activity theory focuses on activity systems, this theory can help us to identify contradictions in the complex situation of learning about patient safety during clinical practice. With the aim to gain more insight in how learning about patient safety results from workplace based learning situations, our research questions were formulated as follows: (1) How do final year medical students perceive patient safety issues during their senior clerkship? (2) How can activity theory further explain and structure these perceptions?

\section{Methods}

Socio-cultural theory was chosen as the conceptual orientation because of its relevance to informal learning in complex social systems. The main focus was activity theory considering its ability to explore tensions in such systems. Other socio-cultural theories, such as situated learning and communities of practice (Lave and Wenger 1991; Wenger 1998) provide some additional sensitising concepts as they focus, more than activity theory, on the development of independence in such settings. According to Lave and Wenger (1991, 1998), medical students enter communities of practice as 'legitimate peripheral participants', and become progressively more integrated into them as they develop the sense of identity of a doctor. This will be further elaborated upon in the discussion.

\section{Ethical approval}

This study was exempt from ethical board review under Dutch law, because no patients were directly involved. We obtained written informed consent from all participants. The 
consent form clearly stated that participation was voluntary and could be withdrawn at any time. There was no professional relationship between researchers and participants, and the participants were in no way dependent on the researchers for their clerkship grades.

\section{Study context}

The study was conducted in the final year of the undergraduate medical curriculum of Maastricht University, the Netherlands. Like all Dutch medical schools, Maastricht medical school offers a 6 year undergraduate medical curriculum, leading to the MD degree. During the first three years (Bachelor phase) the curriculum mainly deals with basic sciences and theoretical aspects of medicine. During the next three years (Master phase), students undertake clinical clerkships in clinical and community settings. The final year consists of two 18 week electives: (1) participation in research in a department of the student's choice; (2) a senior clerkship in a department of the student's choice with students' responsibilities at an intermediate level between junior clerkships and residency.

\section{Participants}

Because students are most likely to encounter problems of patient safety during a transitional stage of their training, we invited final year students, who are at a transitional stage between regular clerkship and residency, to take part in a focus group. Participation being voluntary, the participants were a convenience sample. We conducted as many focus groups as we needed to accommodate all the students that volunteered to participate. Thematic saturation was achieved as no new themes emerged during the fourth and final focus group. Students received a small fee for their participation.

\section{Procedure}

We sent an email inviting all final year students to take part in a focus group to discuss issues of patient safety they had encountered during senior clerkship. We conducted a total of four focus group sessions, which were scheduled on evenings to ensure that attendance did not interfere with clerkship duties.

In the focus groups students were asked to report what they thought patient safety entails, their experiences with situations in which patient safety was compromised and with situations in which errors were made, and their own role and that of the supervisor with regard to patient safety. The discussions were facilitated by an experienced moderator (WG, an educationalist) and lasted approximately $2 \mathrm{~h}$. The primary investigator (JF, a medical doctor) took notes, but did not participate in the discussions.

Analysis

All discussions were recorded and transcribed verbatim and the transcripts were entered into qualitative data analysis software (Atlas.ti 6.0). JF used constant comparative analysis (Strauss and Corbin 1997) to identify and code the topics that were discussed. After all transcripts were coded, every transcript was analyzed for a second time to ensure that all newly derived codes that came up in later transcripts were also checked in earlier transcripts. After WG had also analysed all the transcripts, the two researchers reached agreement on coding through discussion. The emerging themes were incorporated in a model (Fig. 2), and all the researchers (JF, WG, RK (a professor of Internal Medicine) and 


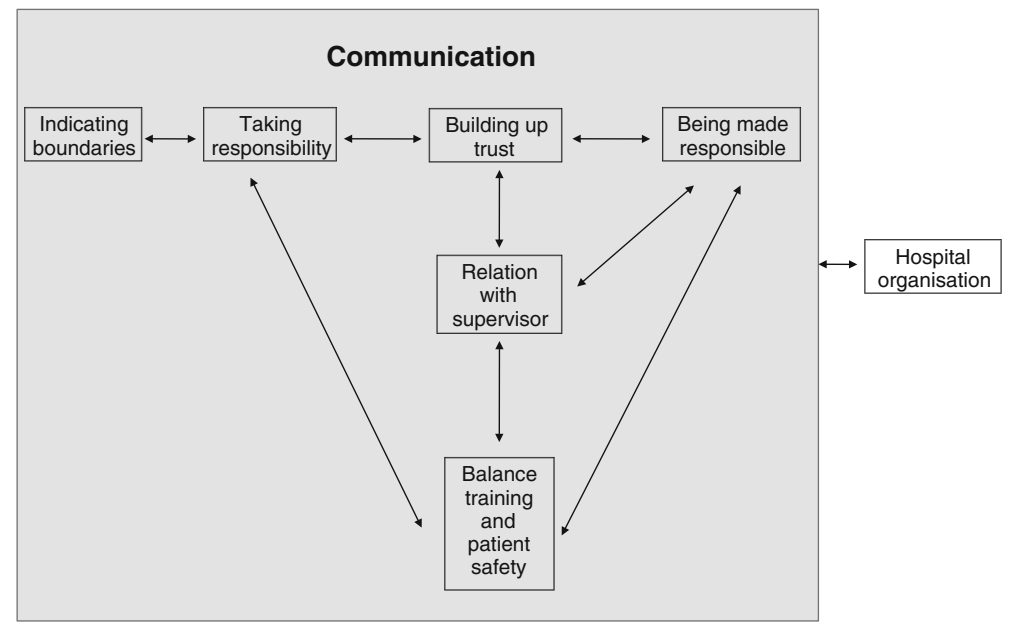

Fig. 2 Model of the relations between the different themes
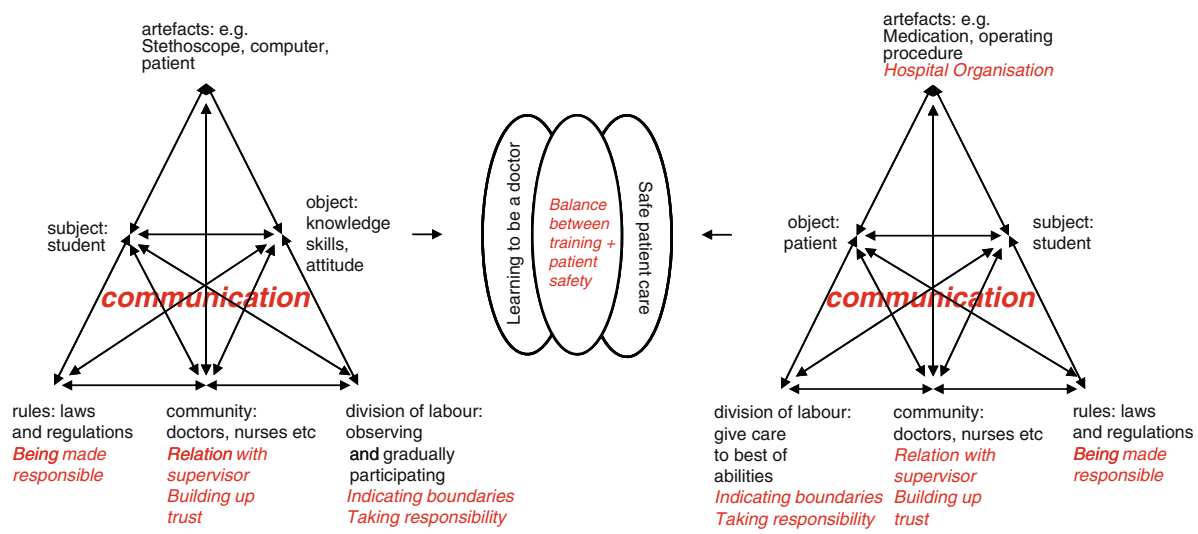

Fig. 3 Third generation activity system adapted from Engeström (2001). Triangle on the left activity system of learning to be a doctor. Triangle on the right activity system of safe patient care. The themes we identified are in italics

AS (a medical doctor and professor of medical education)) discussed the themes and their mutual relations until a consensus was reached. To ensure that the model was an accurate reflection of the focus group discussions, we performed a member check, explaining the model to the participants and inviting their comments. We received responses from eight participants, who stated that the model was an accurate reflection of the discussions. Suggestions by participants led to modification of some of the visual aspects of the model.

After the first inductive analysis, we used the AT framework for a more deductive analysis of the results. A second generation activity system (Fig. 1) (Engeström et al. 1999) did not yield a satisfactory explanation of the relations between the different themes, because it could not accommodate the presence of two simultaneous, mutually influencing activities. We therefore used a third generation activity system (Fig. 3) (Engeström 2001), 
in which two activities could be positioned opposite each other to reveal both the commonalities of and the contradictions between the activities.

\section{Results}

Thirty-four students participated in four focus groups. Their mean age was 24.3 years, and their senior clerkships were equally distributed over surgical and non-surgical specialties.

After reporting the eight themes that emerged from the focus groups, we will discuss our findings in light of activity theory. The themes emerging from the focus groups will be discussed successively in: topics directly relating to the student, the relation with the supervisor and the role of communication, the balance between training of the students and patient safety, and, finally, the organisation of the hospital.

\section{Indicating boundaries}

Students recognised that in order to ensure patient safety it was important for them to indicate the boundaries of their own abilities. They had to determine what they could, and could not, do and make this clear to their supervisors. This can be conceptualised as "selfefficacy", a term used by Bandura $(1986,1997)$ to describe people's perceptions of their ability to accomplish a certain task.

It is often said by me and by other students. You have to be able to indicate your own boundaries very well, within the responsibilities that you get pushed over. And, personally, I think that is a good thing, indeed you have to learn where your boundaries are and know where... What you can and cannot handle. (FG3 P4)

\section{Taking responsibility}

Students' ability to indicate boundaries influenced their ability to indicate which responsibilities they were, and were not, prepared to take on. However, students reported that they were occasionally pressured to reset their own boundaries. In the absence of medical staff, for example, students occasionally felt obliged to take on responsibilities beyond their abilities, simply because there was no one else to perform a certain task. When that happened, they felt forced into the role of a doctor rather than a student. This type of pressure might increase due to a lack of clarity for hospital staff members about the tasks the student was allowed to perform without supervision.

It has become very clear to me during senior clerkship that you can be given a lot of responsibility because of attendings' and residents' high workloads. You are given many tasks and it is up to you to make clear how much responsibility you are prepared to take. (FG3 P10)

[...] I had this patient once, who suddenly got much worse and I happened to be in the outpatient clinic and there were no residents on the ward. I was the first to be called. At that point I thought, well, I don't think this is a good idea. [...] Then I thought: "apparently my role has not been understood properly these last few weeks, if I am the first person to be called when a patient is critical". That really made me think... (FG1 P7) 


\section{Being made responsible}

Taking responsibility was closely associated with 'being made responsible'. Students mentioned their increased responsibility during senior clerkship compared to the previous rotations, because now they were allowed to perform more tasks independently. This valuable increase in responsibility, however, could be in conflict with the boundaries students had set for themselves and with what the students were legally allowed to have. For example, students were occasionally expected to write prescriptions even though it was illegal for them to do so. Students stressed that it was often difficult for them to stand firm and persist in their refusal to sign prescriptions. They thought that lack of clarity about their role might be to blame for this responsibility problem.

Figure 2 shows how the increase in independence the students experience when being made more responsible, is influenced by the trust the students have built up with their supervisors and the relation with their supervisor.

\section{Building up trust}

Another central theme was the building up of trust between student and supervisor. Students realised they had to earn their supervisor's trust. They expected that initially they had to show what they were worth and that supervision would be quite intensive. However, they also expected supervision to slacken as they showed what they were capable of. Students also relied on their supervisors to respond promptly to requests for supervision. The fact that this expectation was not always met, could pose a potential threat to patient safety.

[...]A supervisor assesses what you can and cannot do during the first few weeks. After that he may give you more responsibility and then I don't expect him to turn up at every sneeze to check up on what I'm doing. (FG1 P8)

In other words, students were aware that it took time to build up trust between themselves and their supervisors, and that trust had to be established before they could be given responsibility. Without trust, students were unlikely to be allowed to perform tasks and therefore unlikely to learn. Students also needed assurance that their supervisor trusted them to perform well in order to feel confident to take on responsibilities. Figure 2 shows that trust building influences and is influenced by students taking responsibility and being made responsible, while it also depends on the student supervisor relationship.

\section{Relation with supervisor}

Students' ability to gain their supervisors' trust depended strongly on the quality of the relationship with the supervisor. According to students it was important for them and their supervisors to enter into a dialogue about how to approach different tasks and about the appropriate degree of supervision. When a student felt inhibited to ask for supervision, because of a poor relation with the supervisor, they might be tempted to take risks they would never have taken otherwise.

[...] If you get along well with your supervisor, it is much easier to go to them and ask questions. If there is like no barrier, if you can ask anything. When your supervisor makes things difficult for you and says things like "Are you still not able to do this?" 
then you are unlikely to go to them and there is a bigger risk of something going wrong. At least that is what I am hearing all the time from other students, that it really depends on how your supervisor treats both you and other staff. (FG1 P9)

In summary, the student supervisor relationship influenced the building up of trust and the amount of responsibility a student was given. However, the relation with the supervisor was created by the communication between the student and the supervisor.

\section{Communication}

Communication was mentioned very often by the students, especially in relation to two topics. Firstly, students noticed that miscommunication could lead to medical errors.

Well, I've seen so many errors in communication. Just relations between nurses and that information is not passed on, or passed on incorrectly and then ... [something can go wrong]. (FG4 P4)

Secondly, communication was crucial to learning as it influenced the relation with their supervisor and how well they were able to indicate their own boundaries. The communication theme pervaded all the focus group discussions. Good communication was said to ensure that patient safety was compromised as little as possible, whereas bad communication was identified as one of the main threats to patient safety. Figure 2 illustrates how communication influenced all the themes in the grey area. For example, poor student supervisor communication could influence their dialogue and undermine mutual trust. This, in turn, could cause confusion about the student's role, which impacted on the responsibilities given to and taken on by the student. If students felt they had to take on a responsibility that they were not allowed to or felt they could not ask for supervision, they might be tempted to take inappropriate risks, causing an unsafe situation for patients.

\section{Balance between training and patient safety}

Another important aspect was the balance between their learning to be a doctor, their training, and their fear to harm patients during this process. Students accepted that they were bound to make mistakes when performing tasks as part of their learning process. The severity of potential consequences, however, determined how quick students were to ask for supervision. For example, students were more inclined to do so when a baby's life was at risk during labour than when there was a risk of wound infection. Some students were reluctant to approach their supervisor with questions, because they felt the supervisor had a low opinion of their performance or because they thought asking questions might impact negatively on their final grade. When this occurred, students experienced tension between their role as a learner and their responsibility to take good care of their patient. They had to learn to keep the balance between their training and patient safety. This balance was influenced by the amount of responsibility they were being given and took on and by the relation with their supervisor.

I think you have to learn that you should just say such things. That it's about the patient and not about what someone might think of you. If you feel you have to intervene at a certain moment, or that you have to double check, then you should just 
go and do that. For some people this can be very difficult. Basically, you put your image or even your final grade on the line. (FG1 P9)

\section{Hospital organisation}

The final theme relates to students' experiences in relation to communication between hospital departments. Students observed that departments are organised differently and could therefore work against one another and lead to an unsafe environment. They also noted that a discontinuity of care, due to the rotation of residents and staff, could pose a risk for patients' safety. Finally, they observed that poor communication between departments could lead to mistakes or delay in treatment resulting in harm to patients. In the following quotation, a student who recommended treatment with antibiotics, describes the reaction of a patient who had just been told by another department he did not need antibiotics:

[...]So, this patient became furious with us! Yes, because, we weren't communicating well enough between the different departments. Well, I could really imagine that [he became really angry]. That kind of thing [poor communication between departments] happens a lot, I think... (FG4 P4)

The experiences in students' immediate surroundings can be seen as a so-called microlevel, represented by the themes in the grey area in Fig. 2. In contrast, students also mentioned some situations that could be placed on a more macro level, such as interdepartmental problems. Because communication played a very important role in these problems, it is also shown as influencing "hospital organisation" in Fig. 2.

\section{Activity theory}

Based on our AT analysis, we distinguished two different activities that can provide insight into how the complex system of workplace learning can affect patient safety: the activity of learning to be a doctor and the activity of taking care of patients without doing harm. Because these two activities usually coincide, tension can arise since they are directed at different goals. At this point the student finds himself in the middle of a force field and has to be adaptive to try to achieve a balance between his training and possible harm to the patient. A system in which these two mutually influencing activities are incorporated is presented in the third generation AT model (Engeström 2001) in Fig. 3.

Figure 3 shows the student as the subject of the two activities. The activity system on the left shows how a student with the goal of learning to be a doctor, tries to change his knowledge, skills and attitude (object) using different tools (artefacts), such as a stethoscope, a textbook or even a patient. Changes in skills, knowledge and attitudes are influenced by the prevailing rules in the hospital, and that students need to be given responsibility in order to be able to learn. In addition, knowledge and skills are influenced by the community that the student is a part of, because the relation with the supervisor can either promote or diminish the learning experience. Finally, knowledge and skills are influenced by the different roles of the members of the community. For instance, students are supposed to take some responsibility, but equally to indicate when they consider themselves unable to perform a certain task. Other members of the community, like the supervisor, are expected to teach the student as well as monitor the effects of their teaching. 
The activity system on the right of Fig. 3 is similar to that on the left, but the activity consists of providing safe health care, with the student aiming to change the patient by treatment. This involves tools like medication and diagnostic procedures, but also the way the hospital is organised and how different specialties work together to achieve the best possible outcome for patients.

When the two activities coincide, a contradiction can arise between the student's roles (division of labour) as a doctor and a learner. A student can learn from performing a certain procedure, but the patient may not receive optimal care, due to the higher risk of error when a procedure is performed by a student versus an expert. The different sets of rules of the two activities also influence the process. Although this contradiction poses a risk (to the patient), a well performed procedure is a good learning opportunity (for the student). It is up to the student to find a good balance between the two activities, which can be seen as a third outcome of the co-occurrence of the two activities.

Last, Fig. 3 locates communication in the center of both activity systems. Communication is an essential part of both activity systems and can be presented by every arrow in the activity systems. Just as the culture and history of every subject, community, artefact and rule are part of the activity system, communication is an integral and essential part of the activity (systems).

\section{Discussion and conclusions}

Our analysis of the focus group discussions yielded eight important themes which appeared to be key influences in relation to learning about patient safety. These themes were interrelated and influenced each other, as illustrated by the model in Fig. 2. The use of AT showed how the different themes are mutually connected whilst being part of two different activity systems. The model we developed revealed that students' engagement in two main activities, learning to be a doctor and providing safe patient care, could create contradictions when the rules and the division of labour of one activity adversely affect the other activity. Due to contradictions in roles and rules, an unsafe situation could arise with concomitant stress for the student who had to manage the two activities simultaneously. AT helped to identify these contradictions and thus created a deeper understanding of the factors that influence patient safety in the complex system of workplace learning. This study highlighted only two parts of the activity system as potential causes of contradictions. Further research is needed to identify other interactions between and within the activity systems.

In addition to AT, other theories with relevance to workplace learning, such as communities of practice (CoP) and situated learning (Lave and Wenger 1991; Wenger 1998) can help explain some of the themes we found. There are similarities between students' descriptions of their roles and their expectations of supervisors in this study and the position of the legitimate peripheral participant in situated learning. According to situated learning theory, the legitimate peripheral participant (the student) gains progressively more responsibilities and becomes more and more like a supervisor who can teach other new participants in the community. Additionally, students in our study were aware that they were members of a community in which they had a specific role, but they also felt they contributed to safe patient care by taking care of patients and alerting supervisors to things they had missed. Such an exchange of knowledge, which can occur when newcomers participate alongside experts, is characteristic of a community of practice. Both theories, 
situated learning and $\mathrm{CoP}$, can be seen as extensions of two factors of the activity systems we defined in this study: community and roles.

Other researchers have investigated themes that emerged from our analysis. Stewart's findings (Stewart 2007) about assumptions made when students ask for supervision were echoed by the assumption of the students in our study that supervisors would respond when called upon and that a junior should have "the right level of confidence". Kennedy et al. (2009a) described the pressure on trainees to act independently and the tension between "functioning independently and maintaining good standards of care", confirming the experiences of the students in our study. Another study by Kennedy et al. (2009b) showed how trainees' decisions were influenced by issues like the clinical situation, the desire for independence and the approachability of supervisors, confirming our findings concerning the "balance between training and patient safety" and the "relation with the supervisor".

In addition to themes that were also described in other studies, we identified a new theme as an essential component of our model: the need to build up trust between student and supervisor. Students and supervisors are likely to use different strategies to build up trust, and these are influenced by the educational and work culture of a specific department as well as by the relation between supervisor and student. Trust building strategies and their effects on patient safety should be investigated in further research.

The themes we presented in this study predominantly relate to students' immediate training environment, the micro level, although the students also referred to problems at the macro level of the hospital organisation. The results suggest that students, even at this early transitional phase of their training, already have considerable insight into what goes on in their immediate work environment. In order to increase students' understanding of patient safety issues, education should target areas where students' understanding needs improvement, such as problems arising at organisational level, ways to deal with problems in their immediate surroundings and the precarious balance between learning and patient safety, which proved a major concern for the students in this study. Since fear of errors can prevent students from taking risks and therefore from learning, education should make students aware of this problem and teachers should support them in finding a proper balance. Thus, patient safety problems on an organisational level and balancing training and patient safety are important topics for courses on patient safety for medical students. Further research should investigate the effectiveness of such courses.

The generalisability of our findings is limited, because we conducted the study in only one academic medical centre. However, the fact that our findings are confirmed by other studies suggests that they may be relevant to other settings where students transition from undergraduate to postgraduate education. Another limitation is that our study was confined to undergraduate students' experiences. Supervisors may feel that students' views are distorted and incomplete. Further research will have to establish whether or not there are differences between the experiences of supervisors and students regarding patient safety.

Analysing our findings from the perspective of AT, we discovered contradictions in the activities of students that impact on the learning about patient safety of students during the transition from undergraduate to postgraduate training. Contradictions relating to rules and division of labour were the key outcome of this study. The results of this study offer enhanced insight into the complexities of learning about patient safety. Further studies could build on this, for knowledge of this complex issue is a crucial factor in improving education around patient safety.

Acknowledgments The authors would like to thank Mereke Gorsira for editing the final version of the manuscript and all students for participating in this research. 
Open Access This article is distributed under the terms of the Creative Commons Attribution Noncommercial License which permits any noncommercial use, distribution, and reproduction in any medium, provided the original author(s) and source are credited.

\section{References}

Bandura, A. (1986). Social foundations of thought and action: A social cognitive theory. Englewood Cliffs, NJ: Prentiss-Hall.

Bandura, A. (1997). Self-efficacy: The exercise of control. New York: Freeman.

Brennan, T. A., Leape, L. L., Laird, N. M., Hebert, L., Localio, A. R., Lawthers, A. G., et al. (1991). Incidence of adverse events and negligence in hospitalized patients. Results of the harvard medical practice study I. New England Journal of Medicine, 324(6), 370-376.

Engeström, Y. (2001). Expansive learning at work: Toward an activity theoretical reconceptualization. Journal of Education and Work, 14(1), 133-156.

Engeström, Y., Miettinen, R., \& Punamaki, R.-L. (1999). Perspectives in activity theory. Cambridge: Cambridge University Press.

Fischer, M. A., Mazor, K. M., Baril, J., Alper, E., DeMarco, D., \& Pugnaire, M. (2006). Learning from mistakes. Factors that influence how students and residents learn from medical errors. Journal of General Internal Medicine, 21(5), 419-423.

Hall, L. W., Scott, S. D., Cox, K. R., Gosbee, J. W., Boshard, B. J., Moylan, K., et al. (2010). Effectiveness of patient safety training in equipping medical students to recognise safety hazards and propose robust interventions. Quality and Safety in Health Care, 19(1), 3-8.

Karnieli-Miller, O., Vu, T. R., Holtman, M. C., Clyman, S. G., \& Inui, T. S. (2010). Medical students' professionalism narratives: A window on the informal and hidden curriculum. Academic Medicine, 85(1), 124-133.

Kennedy, T. J. T., Regehr, G., Baker, G. R., \& Lingard, L. A. (2005). Progressive independence in clinical training: A tradition worth defending? Academic Medicine, 80(10), S106-S111.

Kennedy, T. J., Regehr, G., Baker, G. R., \& Lingard, L. (2009a). Preserving professional credibility: Grounded theory study of medical trainees' requests for clinical support. British Medical Journal, 338, b128.

Kennedy, T. J., Regehr, G., Baker, G. R., \& Lingard, L. A. (2009b). 'It's a cultural expectation...' The pressure on medical trainees to work independently in clinical practice. Medical Education, 43(7), $645-653$.

Kerfoot, B. P., Conlin, P. R., Travison, T., \& McMahon, G. T. (2007). Patient safety knowledge and its determinants in medical trainees. Journal of General Internal Medicine, 22(8), 1150-1154.

Kohn, K. T., Corrigan, J. M., \& Donaldson, M. S. (1999). To err is human. Building a safer health system. Washington, DC: National Academy Press.

Lave, J., \& Wenger, E. (1991). Situated learning. Legitimate peripheral participation. Cambridge: Cambridge University Press.

Leape, L. L. (2009). Errors in medicine. Clinica Chimica Acta, 404(1), 2-5.

Luthy, C., Perrier, A., Perrin, E., Cedraschi, C., \& Allaz, A. F. (2004). Exploring the major difficulties perceived by residents in training: A pilot study. Swiss Medical Weekly, 134(41-42), 612-617.

Mennin, S. (2010). Self-organisation, integration and curriculum in the complex world of medical education. Medical Education, 44(1), 20-30.

Pingleton, S. K., Horak, B. J., Davis, D. A., Goldmann, D. A., Keroack, M. A., \& Dickler, R. M. (2009). Is there a relationship between high-quality performance in major teaching hospitals and residents' knowledge of quality and patient safety? Academic Medicine, 84(11), 1510-1515.

Reason, J. (2008). The human contribution. Unsafe acts, accidents and heroic recoveries. Surrey: Ashgate.

Stewart, J. (2007). Don't hesitate to call—the underlying assumptions. The clinical teacher, 4, 6-9.

Strauss, A., \& Corbin, J. M. (1997). Grounded theory in practice. Thousand oaks, CA: Sage.

Vygotsky, L. S. (1978). Mind in society. The development of higher psychological processes. Cambridge, MA: Harvard University Press.

Walton, M. (2007). Teaching patient safety to clinicians and medical students. The clinical teacher, 4, 224-231.

Walton M., Flanagan B., Harrison J., Roberts C., Shaw T., Barnet S. et al. (2008) WHO patient safety curriculum guide for medical schools. World Health Organization. Retrieved January 18, 2010, from http://www.who.int/patientsafety/education/medical_curriculum_form/en/index.html.

Wenger, E. (1998). Communities of practice. Learning, meaning and identity. Cambridge: Cambridge University Press. 